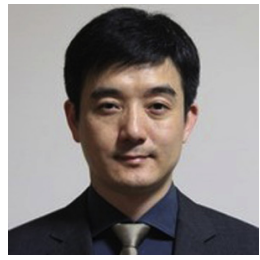

\section{IS THE ERA OF THE HEART} TEAM COMING?

\section{To the Editor:}

A multidisciplinary team approach for the management of patients with tumor has been found to significantly improve the prognosis of these patients. ${ }^{1}$ Following suit, a team approach has been introduced to the heart disease field because of the complexity of heart failure and congenital heart diseases. The 2010 European Society of Cardiology and European Association of Cardio-Thoracic Surgery (ESC/EACTS) guidelines on myocardial revascularization recommended that patients with stable, severe coronary artery disease accept the most appropriate therapy after discussion with a heart team (Class I, Level C). ${ }^{2}$ This concept was further strengthened in the 2011 joint American College of Cardiology Foundation/ American Heart Association/Society for Cardiovascular Angiography and Interventions (ACCF/AHA/SCAI) guidelines and the 2014 updated version of the joint ESC/EACTS guidelines. $^{3,4}$

With the development of technology, more therapy choices have been proposed for stable coronary artery diseases, including coronary artery bypass grafting (on-pump, off-pump, or minimally invasive operations), interventional therapy, and drug therapy. Every physician and patient cares about how to develop the best therapeutic strategy to benefit patients to a maximum extent. This has been well addressed by heart teams.

Generally, heart teams consist of cardiologists, interventional cardiologists, and cardiac surgeons. This team approach may have significant advantages. A team may better interpret examination results and specific conditions (such as cardiac functional grading and other combined diseases) and develop the best therapeutic strategy that combines local therapeutic capability and patient preferences while avoiding professional bias that may come if all professionals involved are from a single department. ${ }^{5}$ All of this is more likely to accord with the principles of autonomy, beneficence, nonmaleficence, and justice. ${ }^{6}$

Several retrospective analyses of clinical trials comparing different strategies of myocardial revascularization (such as the Synergy Between Percutaneous Coronary Intervention with Taxus and Cardiac Surgery and Medicine, Angioplasty, or Surgery Study II trials) provide direct evidence that the therapeutic strategies developed after discussion by a heart team can improve the prognosis of patients. ${ }^{7,8}$ Initially, the role of that heart team was to assess whether patients could be enrolled into the corresponding clinical studies. Interestingly, the patients who were excluded from the clinical studies and accepted the recommendation of the heart team had a higher survival rate than those who were enrolled in the studies and randomly accepted different therapeutic procedures. These results, although suggestive to a certain extent, are still insufficient evidence for showing interventional effects of a heart team, which must be assessed from the following aspects with more studies and data: repeatability of the therapeutic strategies for specific cases developed by the heart team, assessment of the difference between the therapeutic strategies with and without involvement by the heart team, comparison of therapeutic strategies and prognosis of patients in the same heart center before and after establishment of the heart team, and comparison of therapeutic strategies and prognosis of patients in different centers with and without heart teams.

Studies conducted in the United Kingdom by Yates and colleagues ${ }^{9}$ showed that a majority of patients with severe coronary artery diseases did not abide by the suggestion in the ESC/EACTS guidelines on myocardial revascularization to accept the discussion and assessment of the heart team. In addition, analyses of the Organization of Economic Cooperation and New York State Registration Data ${ }^{10}$ demonstrate that myocardial revascularization operations in Europe and the United States are generally not strictly in accordance with the standardization provided in the guidelines. This highlights a very realistic problem: How do we integrate guideline recommendations into clinical practice, so clinical practices do not deviate from the guidelines?

Currently there is a lack of a real sense of a specific heart team approach in China. Generally, patients who are judged to be unsuitable for percutaneous coronary intervention by an interventional physicians will be transferred to cardiac surgery. Seventy percent of patients with disease involving 3 vessels and left main coronary artery disease accept percutaneous coronary intervention therapy, where the proportion of the stent to coronary artery bypass grafting is about 7:1, which is significantly higher than that in other countries. Given that there exists great regional difference for cardiac surgery development in China, a certain proportion of hospitals capable of interventional therapy are still not able to implement coronary artery bypass grafting, so clearly it is a great challenge to establish heart teams in these hospitals. Fortunately, application of hybrid operations (either 1 stop or multistop) seems to indicate the rudiments of a heart team approach.

The concept of a heart team is still in an exploratory stage in China, where the team's composition, operation, distribution of responsibilities, and other issues still need to be resolved. We should continue to explore the role of heart teams, making better use of them as a medical resource and in developing optimal treatment strategies to maximize patient benefits. 
Zhe Zheng, $M D, P h D$

Chenfei Rao, $M D$

Junzhe Du, MD

Department of Cardiovascular Surgery

Fuwai Hospital

National Center for Cardiovascular Diseases Chinese Academy of Medical Sciences and Peking Union Medical College Beijing, China

\section{References}

1. Kesson EM, Allardice GM, George WD, Burns HJ, Morrison DS. Effects of multidisciplinary team working on breast cancer survival: retrospective, comparative, interventional cohort study of 13722 women. BMJ. 2012;344: e2718.

2. Kolh P, Wijns W, Danchin N, Di Mario C, Falk V, Folliguet T, et al. Guidelines on myocardial revascularization. Eur J Cardiothorac Surg. 2010;38(Suppl): S1-52.

3. Levine GN, Bates ER, Blankenship JC, Bailey SR, Bittl JA, Cercek B, et al. 2011 ACCF/AHA/SCAI guideline for percutaneous coronary intervention: a report of the American College of Cardiology Foundation/American Heart Association Task Force on Practice Guidelines and the Society for Cardiovascular Angiography and Interventions. Circulation. 2011;124:e574-651.
4. Windecker S, Kolh P, Alfonso F, Collet JP, Cremer J, Falk V, et al. 2014 ESC/ EACTS guidelines on myocardial revascularization. Rev Esp Cardiol (Engl Ed). 2015;68:144.

5. Tong BC, Huber JC, Ascheim DD, Puskas JD, Ferguson TB Jr, Blackstone EH, et al. Weighting composite endpoints in clinical trials: essential evidence for the Heart Team. Ann Thorac Surg. 2012;94:1908-13.

6. Beauchamp T, Childress J. Principles of biomedical ethics. 4th ed. New York: Oxford University Press; 1994.

7. Farooq V, Serruys PW, Bourantas CV, Zhang Y, Muramatsu T, Feldman T, et al. Quantification of incomplete revascularization and its association with five-year mortality in the Synergy Between Percutaneous Coronary Intervention With Taxus and Cardiac Surgery (SYNTAX) Trial validation of the residual SYNTAX score. Circulation. 2013;128:141-51.

8. Yates MT, Balmforth D, Soppa GK, Uppal R, Desai J, Jahangiri M. Heart team discussion of patients with severe coronary artery disease in the United Kingdom, following guidelines on myocardial revascularization - a multicenter study [Withdrawn September 30, 2015]. J Thorac Cardiovasc Surg. November 1, 2014 [Epub ahead of print].

9. Hannan EL, Racz MJ, Gold J, Cozzens K, Stamato NJ, Powell T, et al. Adherence of catheterization laboratory cardiologists to American College of Cardiology/ American Heart Association Guidelines for Percutaneous Coronary Interventions and Coronary Artery Bypass Graft Surgery: what happens in actual practice? Circulation. 2010;121:267-75.

10. Organisation for Economic Cooperation and Development. Health at a glance 2009: OECD indicators. Paris, France: OECD Publishing; 2009.

http://dx.doi.org/10.1016/j.jtcvs.2015.07.091 